\title{
Stereoselective Arene-Forming Aldol Condensation: Catalyst-Controlled Synthesis of Axially Chiral Compounds
}

Reto M. Witzig, Dominik Lotter, Vincent C. Fäseke and Christof Sparr[a]

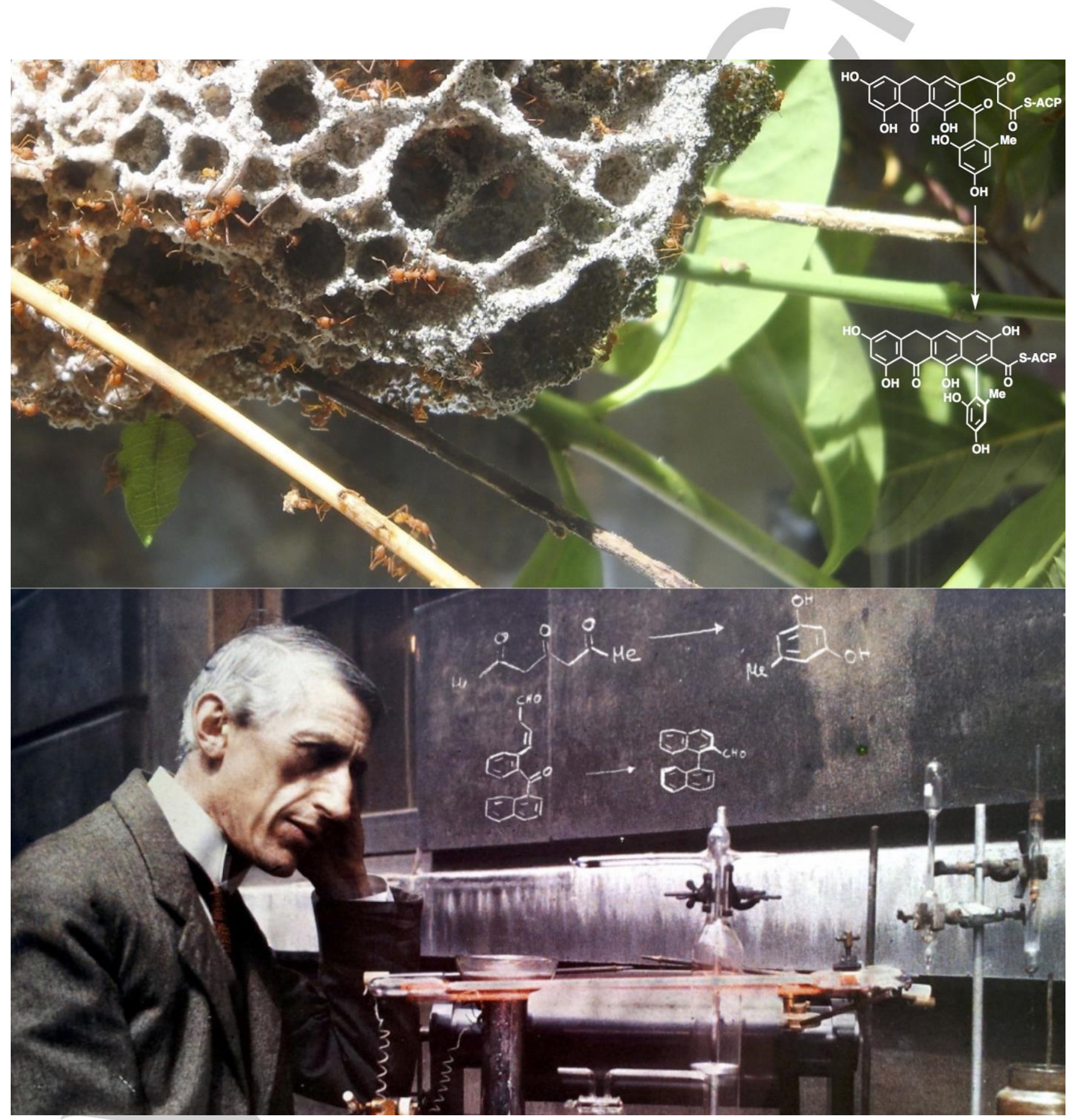


Abstract: The fundamental role that aldol chemistry adopts in various disciplines, such as stereoselective catalysis or the biosynthesis of aromatic polyketides, illustrates its exceptional versatility. On one hand, numerous aldol addition reactions reliably transfer the stereochemical information from catalysts into various valuable products; on the other, countless aromatic polyketide natural products are produced by an ingenious biosynthetic machinery based on arene-forming aldol condensations. With the aim of complementing aldol methodology that controls stereocenter configuration, we recently combined these two tenets by investigating smallmolecule catalyzed aldol condensation reactions that stereoselectively form diverse axially chiral compounds by construction of a new aromatic ring.

\section{Introduction}

Atropisomers, by definition separable stereoisomers that arise from the restricted rotation about a single bond, have become indispensable compounds in various areas of application. ${ }^{[1]}$ They facilitate the synthesis of a wide range of valuable products as chiral ligands used in stereoselective catalysis or serve human medicine as therapeutics with a well-defined molecular shape, such as the antibiotic vancomycin. ${ }^{[2]}$ However, compared to the variety of methods that control stereocenter configuration, many stereoselective methods to prepare the individual compound classes with one or more stereogenic axes remain to be developed. Currently, efforts to design catalytic methods were mostly devoted on the preparation of axially chiral biaryls by kinetic resolution, ${ }^{[3]}$ desymmetrization, ${ }^{[4]}$ cross-coupling, ${ }^{[5]}$ $[2+2+2]$-cycloadditions ${ }^{[6]}$ or the conversion of stereodynamic biaryls into configurationally stable atropisomers. ${ }^{[7]}$ With novel catalyst-controlled methods to selectively prepare a variety of atropisomeric structures, the full potential of this burgeoning class of compounds can be unleashed for future applications.

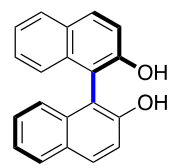

$(+)-\left(R_{\mathrm{a}}\right)-\mathrm{BINOL}$

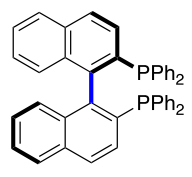

$(+)-\left(R_{\mathrm{a}}\right)$-BINAP

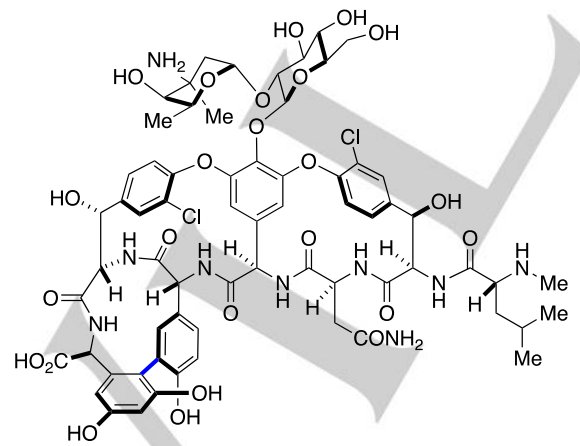

Vancomycin

Figure 1. Selected atropisomers used as ligands in stereoselective catalysis (BINOL, BINAP) and in human medicine (antibiotic vancomycin).

\section{Atropisomerization}

Most applications profit from atropisomeric scaffolds when they are well-behaved chiral motifs throughout the entire temperature range of operation. It is hence crucial at the outset, to assess the relevant bonds for their propensity to rotation. Usually, restricted rotation to provide configurationally stable atropisomers results from strong steric interactions of nearby groups. Hence when considering the rotational profile of the bonds in question, a minimum of two large barriers are required to hinder rotation in both directions. To ensure high configurational stability in the case of biaryls, typically three or four ortho-substituents are hence necessary to sufficiently prevent atropisomer interconversion. For comparison, the bond rotational profile of a di-ortho-substituted biaryl is characterized by just one large barrier, and thermal atropisomerization thus occurs within seconds to minutes at ambient temperature (101 $\mathrm{kJmol}^{-1}$, Figure 2). A third ortho-substituent usually provides the required second rotational barrier to suitably restrict rotation over a broad temperature range. A fourth ortho-substituent finally leads to two simultaneous steric interactions in both directions, which define the rotational barriers leading to increased configurational stability.

While the number of substituents provides a first estimate, the rate of thermal atropisomerization is additionally influenced by the substituents size and orientation, bond lengths, and, if applicable, solvents. ${ }^{[8]}$

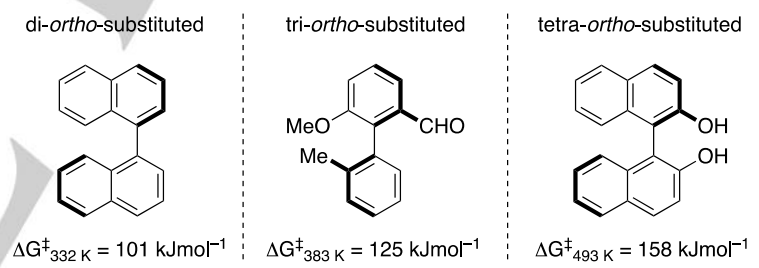

Figure 2. Rotational barriers of selected di-,tri- and tetra-ortho-substituted biaryls.

Besides thermal atropisomerization, the stereochemical integrity of atropisomers is further affected by intra- and intermolecular reactivity. In particular molecules bearing groups which react with each other may equilibrate via transient bridged intermediates that facilitate overall atropisomerization (e.g. hydroxy- and formyl-groups, Scheme 1).[9] Diminished configurational stability hence manifests bridged intermediates with a higher ground state energy or reduced steric repulsion during rotation. Consequently, reactive groups need to be carefully selected or avoided in the reaction design and handling of atropisomers since even tetra-ortho-substituted biaryls may atropisomerize at relevant temperatures as a result of intramolecular reactivity. ${ }^{[10]}$ 


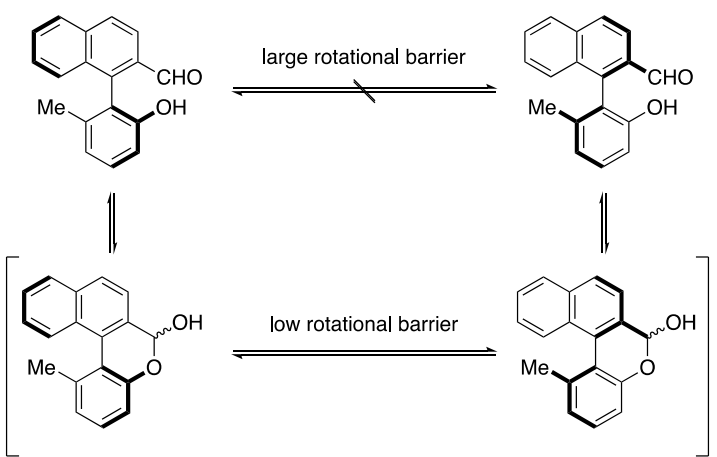

Scheme 1. Atropisomerization through the formation of a biaryl lactol bridge with a lower rotational barrier.

In the case of nonbiaryl atropisomers, reactive groups are often already contained in the molecular backbone. For instance in axially chiral aromatic amides, a significant difference of the half-life of racemization at ambient temperature was observed by altering the reactivity of the ortho-substituents (Figure 3). ${ }^{[11]}$ Specifically, converting the hydroxymethyl-group into a carbaldehyde leads to a substantial decrease of the configurational stability, presumably due to atropisomerization processes via bridged intermediates. ${ }^{[11 \mathrm{~b}]}$ Conclusively, steric repulsion and the reactivity of ortho- with the amide-substituents play a decisive role for the stereochemical integrity of aromatic amides.

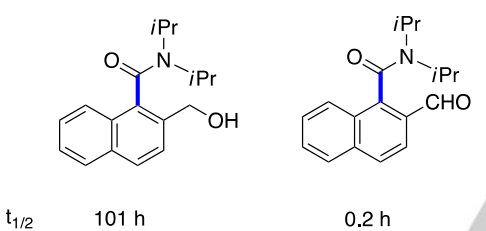

Figure 3. Estimated half-life of racemization of hydroxymethyl- and formylnaphthamides at $20^{\circ} \mathrm{C} .^{[11 \mathrm{~b}]}$

Similarly, bimolecular equilibria to short-lived intermediates with lower rotational barriers provide a means for chemically induced atropisomerization processes. For instance BINOL, which is highly configurationally stable under neutral conditions, racemizes under strong acidic conditions. ${ }^{[12]}$ Furthermore, photochemically induced transient intermediates have been reported as atropisomerization mechanism representatively for larger aromatic hydrocarbons. ${ }^{[13]}$

Taking into account the different atropisomerization mechanisms, novel axially chiral compounds with unique molecular topology are expected to become available by exploring new concepts for their synthesis, for example by emulating biosynthetic reactivity principles.

\section{Biosynthesis of Aromatic Polyketides}

In pioneering studies, Collie discovered that diacetylacetone is converted to the aromatic compound orcinol by an arene- forming aldol condensation in presence of sodium hydroxide (Scheme 2); ${ }^{[14]}$ an observation on which he based his farsighted proposal that poly- $\beta$-ketones are key precursors in the biosynthesis of aromatic polyketides. This biogenic hypothesis was further substantiated by Robinson, Birch, Maitland, Harris and others, ${ }^{[15]}$ and subsequently utilized for several elegant biomimetic syntheses of aromatic compounds. ${ }^{[16]}$

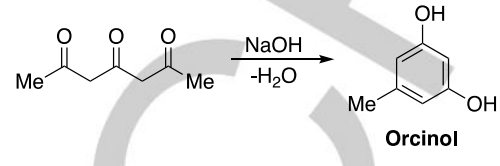

Scheme 2. Collie's synthesis of orcinol from diacetylacetone.

In the biosynthesis of aromatic polyketide natural products, a captivating polyketide synthase (PKS) machinery first assembles poly- $\beta$-ketones to a defined length. The reactive poly- $\beta$-carbonyl chains are then folded into a PKS reaction channel to define the cyclization mode by cyclase/aromatase proteins (CYC/ARO). ${ }^{[17]}$ To illustrate the controlling factors of these PKS-cascades in the context of stereoselectivity, the recently reported atropisomeric natural product fasamycin $\mathrm{C}$ serves as a particularly suitable example. The tridecaketide chain is here folded to provide a putative key intermediate for a final arene-forming aldol condensation, thus resulting in the stereoselective formation of a rotationally restricted tetra-ortho-substituted aromatic polyketide (Scheme 3). Decarboxylation and methylation steps conclude the biosynthesis of the axially chiral tri-ortho-substituted biaryl natural product fasamycin $\mathrm{C}$, which was confirmed to be enantioenriched. ${ }^{[18]}$

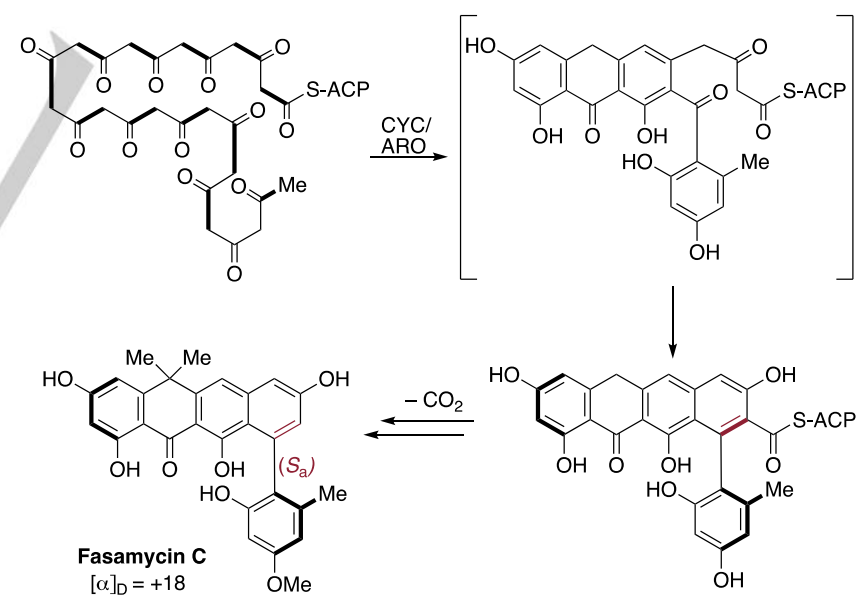

Scheme 3. Putative biosynthesis of fasamycin C. ${ }^{[18]}$

\section{Stereoselective Arene-forming Aldol Condensation: Atropisomeric Biaryls}

By adapting the mechanistic blueprint of this fascinating biosynthetic machinery, we delineated the possibilities of stereoselective arene-forming aldol condensations as synthetic concept. The generic reaction manifold is thus juxtaposed to a prototypical arene-forming aldol condensation to the aromatic 
polyketide orsellinic acid (Scheme 4). The versatility of aldol chemistry for stereoselective catalysis is evident from the many available activation modes. To enable operationally simple amine catalysis, the substrate ideally bears an aldehyde, which generates an activated enamine intermediate. The $\zeta$-keto group provides a means for the formation of a six-membered ring that results in arene-formation upon dehydration. The carbonyl moieties at the $\beta$ - and $\delta$-position, respectively their corresponding tautomeric enol form, are replaceable by different alkene or arene groups and allow substrate diversification. In order to create configurationally stable atropisomers upon arene formation, two different substituents are installed at the terminal position. By combining these considerations with a viable substrate synthesis, various atropisomeric scaffolds may be conveniently prepared in enantioenriched form by a catalytic stereoselective arene-forming aldol condensation.

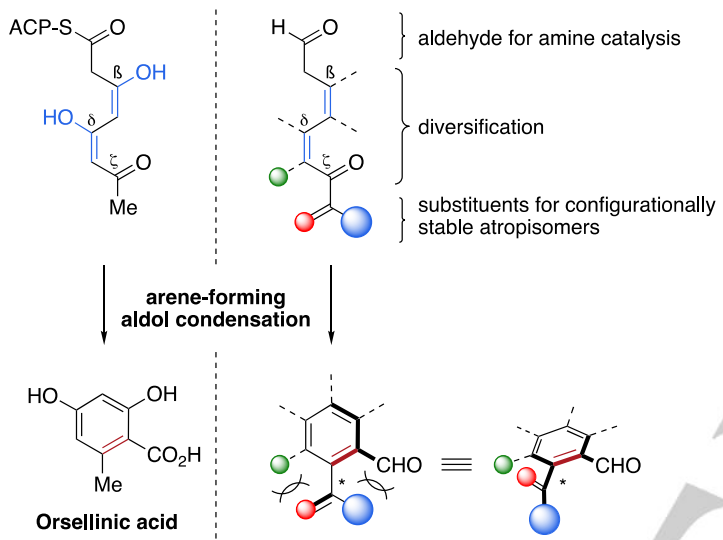

Scheme 4. The generic reaction manifold of the stereoselective arene-forming aldol condensation compared to orsellinic acid biosynthesis.

In order to validate this notion, prototypical biaryls with wellknown configurational stability were explored at the outset of our studies. ${ }^{[19]}$ For product diversification and structurally welldefined substrates, a (Z)-alkene and variable phenyl groups were selected to furnish particularly valuable naphthalene-2carbaldehydes. A 1-naphthyl group provides the required third ortho-substituent, thus giving unsymmetrical binaphthalene-2carbaldehyde products (Scheme 5).

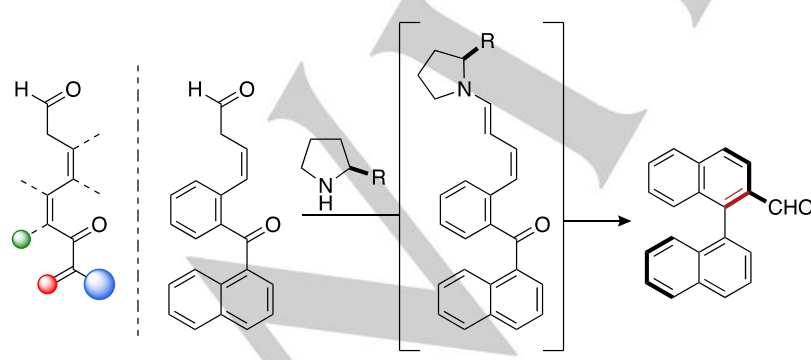

Scheme 5. Secondary amine catalyzed arene-forming aldol condensation furnishing axially chiral 1,1'-binaphthalenes.
The substrates were readily accessible by the addition of a 1,2-dibromobenzene-derived aryl magnesium species to 1naphthaldehyde followed by a Sonogashira cross-coupling with 3-butyn-1-ol and a (Z)-selective semi-hydrogenation of the ensuing alkyne. The ketoaldehyde was subsequently obtained by double oxidation of the diol with Dess-Martin periodinane (Scheme 6).

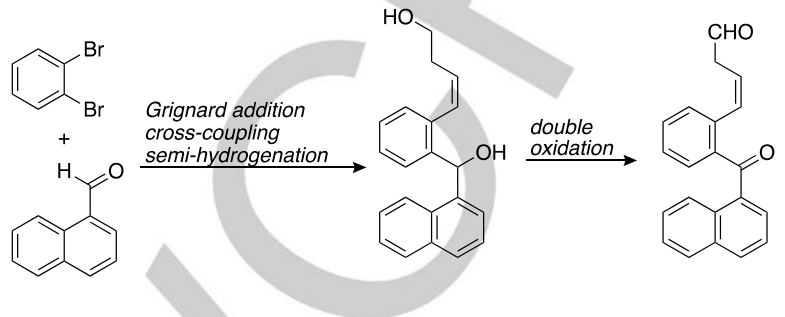

Scheme 6. Substrate synthesis.

While addition of L-Proline was found to provide the desired 1,1 '-binaphthalene-2-carbaldehyde product with a promising 88:12 atroposelectivity, an enantiomeric excess of 99:1 was achieved with 5 mol\% of the (S)-pyrrolidinyl-tetrazole catalyst. ${ }^{[20]}$ Larger secondary amine catalysts showed inferior reactivity in this reaction, presumably due to a structurally encumbered transition state at the aldol addition step. The scope of the reaction embraces substrates with various substituents at the interstitial and terminal aryl groups, with tetra-ortho-substituted biaryl products representing a current limitation of this reaction (Scheme 7).

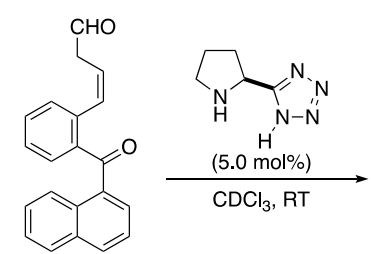<smiles>O=Cc1ccc2ccccc2c1-c1cccc2ccccc12</smiles>
$74 \%$ yield

Representative examples:
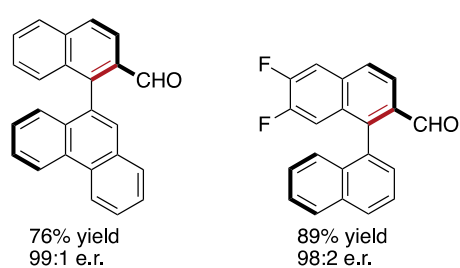

Scheme 7. Scope of the stereoselective arene-forming aldol condensation for atropisomeric biaryls.

These first results supported the notion that the atroposelective arene-forming aldol condensation is a practical method for the preparation of unsymmetrical 1,1'-binaphthalene2-carbaldehydes and that high yields and excellent enantioselectivities are feasible. Due to its flexibility and the mild reaction conditions, it is expected to be useful for a wide range of applications. 


\section{Axially Chiral Aromatic Amides}

To corroborate the generality of the stereoselective areneforming aldol condensation as synthetic concept, the preparation of axially chiral aromatic amides was studied. ${ }^{[21]}$ Furthermore, as aromatic amides are a common motif in medicinal chemistry, an increasing awareness of atropisomerism has been established in drug discovery. ${ }^{[22]}$

In accord with the generic substrate layout, a terminal amide group provides a highly reactive substrate, thus giving tertiary formyl-naphthamides. Additionally, the intramolecular reactivity that affects the configurational stability of the products is balanced by installing a peri-substituent (Scheme 8).<smiles>CC(C)=C(C)C(=O)C(=O)O</smiles>

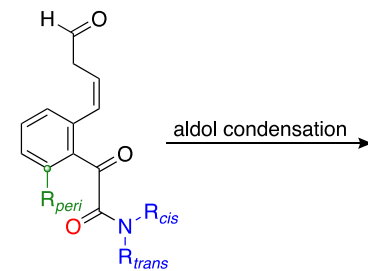

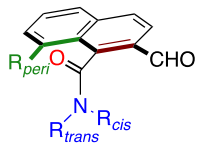

Scheme 8. Arene-forming aldol condensation to form configurationally stable aromatic amides.

The ortho-substituted arylglyoxylic amide substrates were synthesized from aromatic 2,3-furandiones by an initial lactoneopening/triflation sequence. After a Sonogashira cross-coupling with 3-butyn-1-ol followed by a (Z)-selective semi-hydrogenation, the highly reactive $\alpha$-keto-amide substrates were accessible after in situ oxidation (Scheme 9).

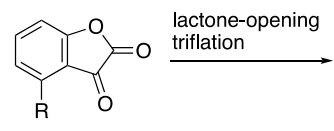
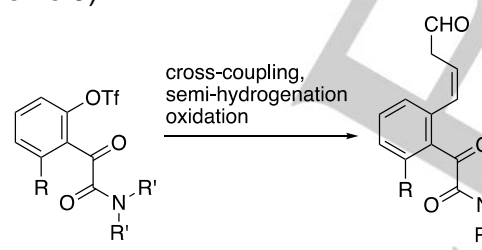

Scheme 9. Synthesis of the ortho-substituted arylglyoxylic amide substrates.

Upon addition of the (S)-pyrrolidinyl-tetrazole catalyst, selective and full conversion of the substrate was observed in presence of $\mathrm{KHCO}_{3}$. Intriguingly, the desired aldol condensation product was obtained with a stereoselectivity of 99:1 in less than two hours at room temperature (Scheme 10). To extend the scope of the process, the resulting ortho-carbaldehyde was subsequently reduced with $\mathrm{NaBH}_{4}$ to form ortho-hydroxymethylsubstituted aromatic amides with higher configurational stability. Using this reaction sequence, even primary-alkyl $\mathrm{N}$-disubstituted aromatic amides and various peri-substituted naphthamides were accessible with excellent enantiopurity.

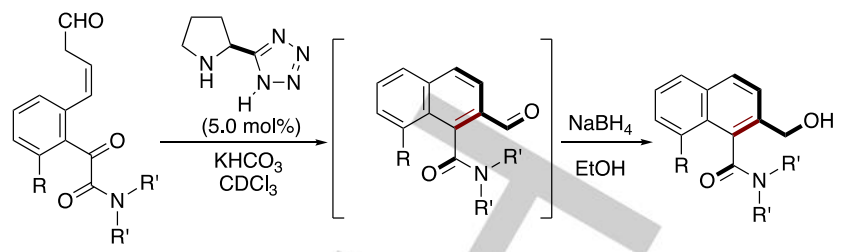

Representative examples:
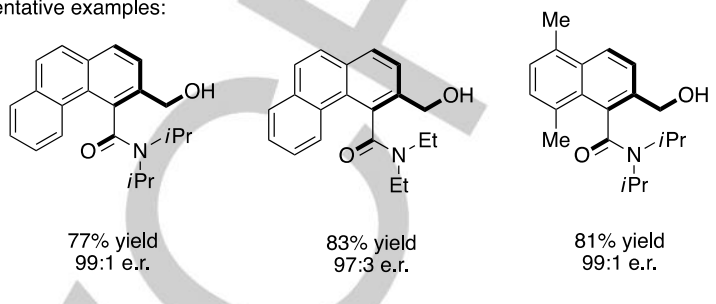

$81 \%$ yield

Scheme 10. Substrate scope of the arene-forming aldol condensation for axially chiral aromatic amides.

The atroposelective synthesis of configurationally stable aromatic amides confirmed that the arene-forming aldol condensation is a valuable synthetic strategy which delivers different axially chiral compounds. Furthermore, the configurational stability of the isolated hydroxy arylamides underlines their use as valuable chiral scaffolds.

\section{Oligo-1,2-naphthylenes}

Ortho-phenylenes belong to a class of helically shaped oligoand polymers utilized in various fields of research (Figure 4a). ${ }^{[23]}$ While many current applications profit from the stereodynamic behavior of these compounds, configurationally stable analogues are of particular interest in order to place substituents into a defined spatial arrangement. ${ }^{[24]}$ The stereodynamic behavior of ortho-phenylenes is explained by the di-orthosubstitution of the biaryl subunits, which only provides one large rotational barrier (Figure $4 b$ ). A third ortho-substituent that is contained in the oligo-1,2-naphthylene structure consequently hinders rotation in both directions. Due to the resulting high rotational barriers, a pronounced configurational stability for each stereogenic axis was expected (Figure 4c). ${ }^{[25]}$

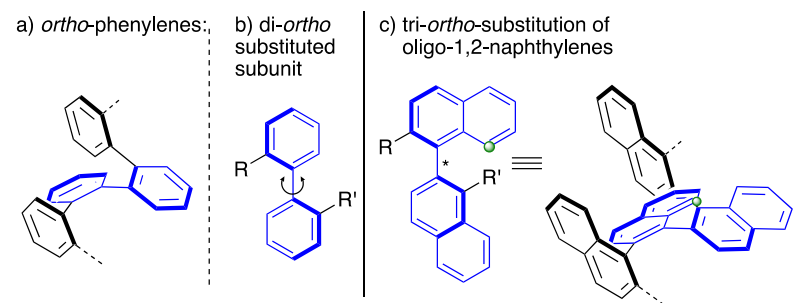

Figure 4. Stereodynamic ortho-phenylenes vs. configurationally stable oligo1,2-napthylenes featuring a third ortho-substituent in each biaryl subunit. 
The arene-forming aldol condensation proved to be an ideal method for the stereoselective synthesis of oligo-1,2naphthylenes. An iterative building block addition/oxidation/ arene-forming aldol condensation sequence allows an efficient and stereoselective synthesis of oligo-1,2-naphthylenes.

For a expedient assembly of the oligomer, an organometallic building block with an alkoxide group was used to circumvent protecting group manipulations (Scheme 11). ${ }^{[26]}$

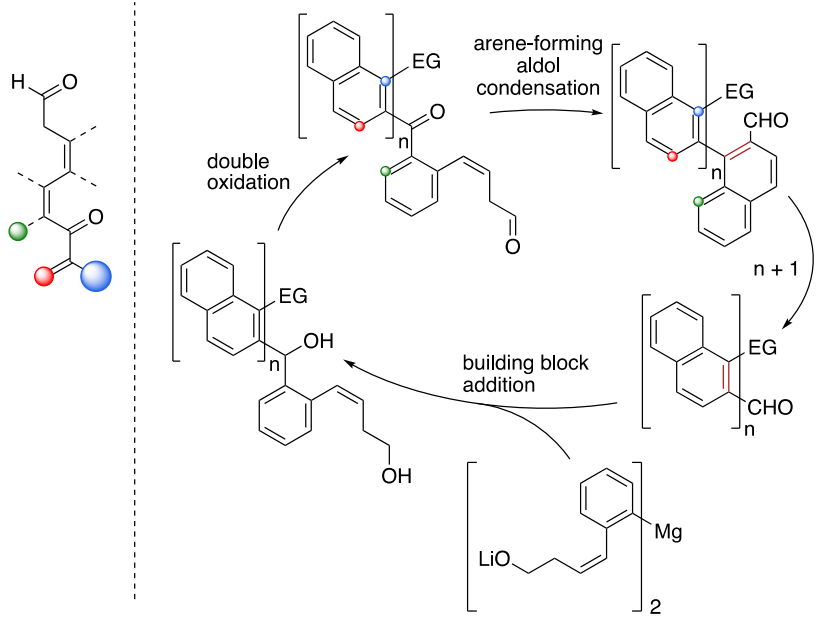

Scheme 11. Strategy for the stereoselective synthesis of oligo-1,2 naphthylenes by a building block addition, double oxidation, aldol condensation sequence.

The substrate for the first aldol condensation was obtained by the addition of the building block to naphthyl-2-carbaldehyde, which serves as end-group for the oligomer with regular 1,2'connectivity. A double oxidation with 2-iodoxybenzoic acid (IBX) and a subsequent arene-forming aldol condensation provided the stereodynamic di-ortho-substituted binaphthalene. With the second building block addition, a precursor for the first enantioselective aldol condensation was obtained.

The diol was oxidized with IBX and initial conditions using $(S)$ pyrrolidinyl tetrazole as catalyst in $\mathrm{CDCl}_{3}$ provided small amounts of the desired ternaphthalene with a first enantioselectivity of 92:8. Furthermore with natural amino acids as catalysts, superior yields were obtained and L-isoleucine was identified as an ideal catalyst considering a combination of yield and selectivity (Scheme 12a). With the ternaphthalene in hand, a remarkably high rotational barrier of $\Delta \mathrm{G}^{ \pm}{ }_{453 \mathrm{~K}}=154 \mathrm{kJmol}^{-1}$ was determined.

The quarternaphthalenes with a second configurationally stable stereogenic axis were particularly interesting, as the diastereoisomers possess distinct molecular topologies. The precursor for this final aldol condensation was prepared as described previously and the aldol condensation was performed under substrate stereocontrol using LDA to yield both diastereomers with a d.r. of 79:21 (Scheme 12b). After separation of the diastereoisomers, the configurational stability was confirmed by their individual analysis in which stereoisomer interconversion was never observed.

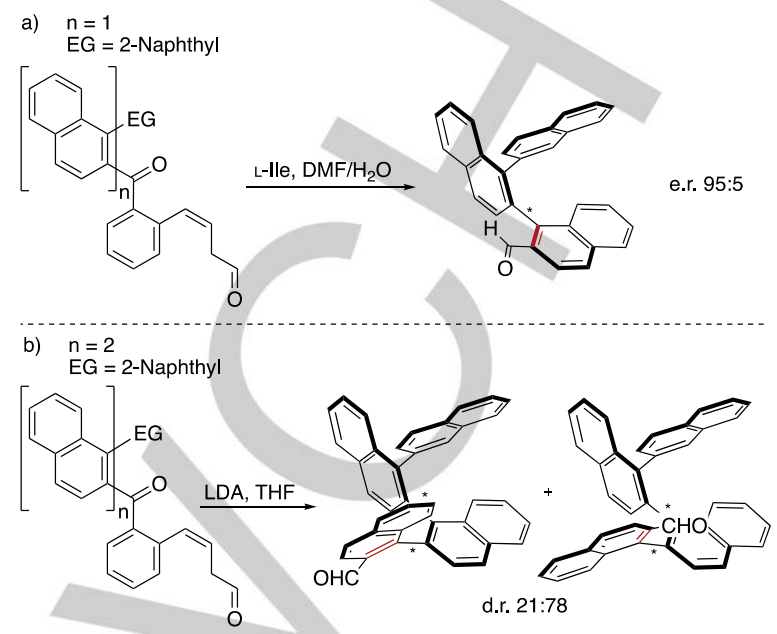

Scheme 12. Catalyst-controlled enantioselective and substrate-controlled diastereoselective arene-forming aldol condensation.

\section{Conclusions and Perspective}

The use of small-molecule catalysts to control atroposelectivity in arene-forming aldol condensation was found to be a viable concept for the synthesis of various rotationally restricted compounds. Presumably, a structurally encumbered transition state of the aldol addition step provides the remarkable levels of selectivity upon activation of the substrate with a chiral catalyst. With the recently reported natural product fasamycin $\mathrm{C}$, the biomimetic nature of this strategy has been confirmed and the discovery of further interesting atropisomeric aromatic polyketide natural products of this type is anticipated.

The variability of the substrate and the mild conditions of these reliable and operationally simple reactions allow the synthesis of a broad range of structurally distinct atropisomers. It is expected that this synthetic concept will be useful for the preparation of a diversity of structurally well-defined compounds with novel topologies for a broad range of future applications.

\section{Acknowledgements}

We thank the Swiss National Science Foundation (200021153519/1) and the University of Basel for financial support and Priv.-Doz. Dr. Daniel Häussinger and Dr. Markus Neuburger for assistance in NMR spectroscopy and X-ray crystallography. P. Jung is acknowledged for generously providing the frontispiece picture (top). The image of J. Norman Collie (frontispiece, bottom) was adapted from UCL Chemistry Collections.

Keywords: aldol reaction • atropisomerism • catalysis • polyketides $\cdot$ stereoselectivity 
[1] G. P. Moss, Pure Appl. Chem. 1997, 68, 2193-2222.

[2] A. Miyashita, A. Yasuda, H. Takaya, K. Toriumi, T. Ito, T. Souchi, R. Noyori, J. Am. Chem. Soc. 1980, 102, 7932-7034; M. Schäfer, T. R. Schneider, G. M. Sheldrick, Structure 1996, 4, 1509-1515.

[3] J. D. Jolliffe, R. J. Armstrong, M. D. Smith, Nature Chem. 2017, 9, 558562; S. Staniland, R. W. Adams, J. J. W. McDouall, I. Maffucci, A Contini, D. M. Grainger, N. J. Turner, J. Clayden, Angew. Chem. Int. Ed. 2016, 55, 10755-10759; Angew. Chem. 2016, 128, 10913-10917.

[4] S. Lu, S. B. Poh, Y. Zhao, Angew. Chem. Int. Ed. 2014, 43, 11041 11045; Angew. Chem. 2014, 126, 11221-11225; desymmetrization of axially chiral N-aryl succinimides: N. Di lorio, F. Champavert, A. Erice, P. Righi, A. Mazzanti, G. Bencivenni, Tetrahedron, 2016, 72, 51915201.

[5] T. Hayashi, K. Hayashizaki, T. Kiyoi, Y. Ito, J. Am. Chem. Soc. 1988, 110, 8153-8156; J. Yin, S. L. Buchwald, J. Am. Chem. Soc. 2000, 122, $12051-12052$.

[6] A. Gutnov, B. Heller, C. Fischer, H.-J. Drexler, A. Spannenberg, B. Sundermann, C. Sundermann, Angew. Chem. Int. Ed. 2004, 43, 37953797; Angew. Chem. 2004, 116, 3883-3886; T. Shibata, T. Fujimoto, K Yokota, K. Takagi, S. Ogaki, J. Am. Chem. Soc. 2004, 126, 8382-8383; T. Suda, K. Noguchi, M. Hirano, K. Tanaka, Chem. Eur. J. 2008, 14, 6593-6596; K. Tanaka, Chem. Asia, J. 2009, 4, 508-518; Y. Shibata, K. Noguchi, K. Tanaka, J. Org. Chem. 2011, 76, 1926-1929.

[7] G. Bringmann, M. Breuning, R. Walter, A. Wuzik, K. Peters, E.-M. Peters, Eur. J. Org. Chem. 1999, 3047-3055; G. Bringmann, D. Menche, Acc. Chem. Res. 2001, 34, 615-624; J. L. Gustafson, D. Lim, S. J. Miller, Science 2010, 328, 1251-1255; R. Miyaji, K. Asano, S Matsubara, J. Am. Chem. Soc. 2015, 137, 6766-6769.

[8] G. Bringmann, A. J. Price Mortimer, P. A. Keller, M. J. Gresser, J. Garner, M. Breuning, Angew. Chem. Int. Ed. 2005, 44, 5384-5427; Angew. Chem. 2005, 117, 5518-5563; M. Rickhaus, L. Jundt, M. Mayor Chimia, 2016, 70, 192-202.

[9] G. Bringmann, D. Vitt, J. Kraus, M. Breuning, Tetrahedron, 1998, 54, 10691-10698; K. Mori, T. Itakura, T. Akiyama, Angew. Chem. Int. Ed. 2016, 55, 11642-11646; Angew. Chem. 2016, 128, 11814-11818

[10] G. Bringmann, T. Hartung, Liebigs Ann. Chem. 1994, 313-316.

[11] a) J. Clayden, J. H. Pink, Angew. Chem. Int. Ed. 1998, 37, 1937-1939; Angew. Chem. 1998, 110, 2040-2043; b) for barriers to rotation of tertiary aromatic amides (estimated half-life for racemization at $20^{\circ} \mathrm{C}$ ), see: A. Ahmed, R. A. Bragg, J. Clayden, L. W. Lai, C. McCarthy, J. H. Pink, N. Westlund, S. A. Yasin, Tetrahedron 1998, 54, 13277-13294; c) R. Rios, C. Jimeno, P. J. Carroll P. J. Walsh, J. Am. Chem. Soc. 2002 124, 10272-10273; d) J. Clayden, Chem. Commun. 2004, 127-135.

[12] A. M. Genaev, G. E. Salnikov, A. V. Shernyukov, Z. Zhu, K. Yu. Koltunov, Org. Lett. 2017, 19, 53.2-535, and references therein.

[13] T. Hattori, Y. Shimazumi, H. Goto, O. Yamabe, N. Morohashi, W. Kawai, S. Miyano, J. Org. Chem, 2003, 68, 2099-2108.

[14] J. N. Collie, J. Chem. Soc. Trans. 1893, 63, 329-337.
[15] R. Robinson, J. Chem. Soc. Trans. 1917, 111, 762-768; A. J. Birch, R. A. Massy-Westropp, C. J. Moye, Austr. J. Chem. 1955, 8, 539-544; A. J. Birch, P. Fitton, D. C. C. Smith, D. E. Steere, A. R. Stelfox, J. Chem. Soc. 1963, 2209-2216; J. R. Bethel, P. Maitland, J. Chem. Soc. 1962, 3751-3758; T. M. Harris, R. L. Carney, J. Am. Chem. Soc. 1967, 89 , 6734-6741.

[16] M. Yamaguchi, T. Okuma, A. Horiguchi, C. Ikeura, T. Minami, J. Org Chem. 1992, 57, 1647-1649; H. Miyatake-Ondozabal, A. G. M. Barrett Org. Lett. 2010, 12, 5573-5575; G. Hilt, D. F. Weske, Chem. Soc. Rev. 2009, 38, 3082-3091.

[17] C. Hertweck, Angew. Chem. Int. Ed. 2009, 48, 4688-4716; Angew. Chem. 2009, 121, 4782-4811.

[18] Enantioenrichment of fasamycin C produced by Streptomyces formicae isolated from the fungus-growing plant-ant Tetraponera penzigi: Z. Qin J. T. Munnoch, R. Devine, N. A. Holmes, R. F. Seipke, K. A. Wilkinson, B. Wilkinson, M. I. Hutchings, Chem. Sci. 2017, 8, 3218-3227.

[19] A. Link, C. Sparr, Angew. Chem. Int. Ed. 2014, 53, 5458-5461; Angew. Chem. 2014, 126, 5562-5565.

[20] H. Torii, M. Nakadai, K. Ishihara, S. Saito, H. Yamamoto, Angew. Chem Int. Ed. 2004, 43, 1983-1986; Angew. Chem. 2004, 116, 2017-2020; A. J. A. Cobb, D. M. Shaw, S. V. Ley, Synlett, 2004, 558-560; A. Hartikka, P. I. Arvidsson, Eur. J. Org. Chem. 2005, 4287-4295.

[21] V. C. Fäseke, C. Sparr, Angew. Chem. Int. Ed. 2016, 55, 7261-7264 Angew. Chem. 2016, 128, 7378-7381.

[22] H. Takahashi, S. Wakamatsu, H. Tabata, T. Oshitari, A. Harada, K. Inoue, H. Natsugari, Org. Lett. 2011, 13, 760-763; S. R. LaPlante, P. J. Edwards, L. D. Fader, A. Jakalian, O. Hucke, ChemMedChem 2011, 6 505-513; J. Clayden, W. J. Moran, P. J. Edwards, S. R. LaPlante, Angew. Chem. Int. Ed. 2009, 48, 6398-6401; Angew. Chem. 2009, 121, 6519-6520; E. Kumarasamy, R. Raghunathan, M. P. Sibi, J. Sivaguru, Chem. Rev. 2015, 115, 11239-11300.

[23] a) A. D. Schlüter, Handbook of Conducting Polymers (Eds.: T. Skotheim, R. Elsenbaumer, J. Reynolds), Marcel Dekker, New York 1997, pp 209-224; b) A. J. Berresheim, M. Müller, K. Müllen, Chem Rev. 1999, 99, 1747-1786; c) M. Rickhaus, M. Mayor, M. Juríček Chem. Soc. Rev. 2016, 45, 1542-1556; d) Z. J. Kinney, C. S. Hartley, J. Am. Chem. Soc. 2017, 139, 4821-4827.

[24] a) Y. Ito, E. Ihara, M. Murakami, M. Shiro, J. Am. Chem. Soc. 1990, 112, 6446-6447; b) Y. Ito, E. Ihara, M. Murakami, Angew. Chem Int. Ed. 1992, 31, 1509-1510; Angew. Chem. 1992, 104, 1508-1510.

[25] D. Lotter, M. Neuburger, M. Rickhaus, D. Häussinger, C. Sparr, Angew. Chem. Int. Ed. 2016, 55, 2920-2923; Angew. Chem. 2016, 128, 29732976.

[26] S. Kato, N. Nonoyama, K. Tomimoto, T. Mase, Tetrahedron Lett. 2002 , $43,7315-7317$ 
1

2

3

4

5

6

7

8

9

10

11

12

13

14

15

16

17

18

19

20

21

22

23

24

25

26

27

28

29

30

31

32

33

34

35

36

37

38

39

40

41

42

43

44

45

46

47

48

49

50

51

52

53

54

55

56

57

58

59

60

61

62

63

64

65

\section{CONCEPT}
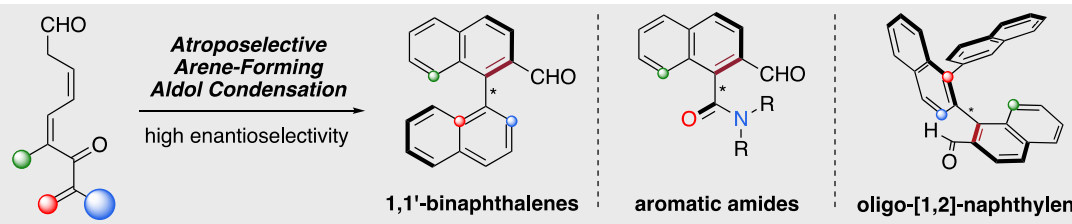

aromatic amides

oligo-[1,2]-naphthylenes

An arena for carbonyl compounds: Intrigued by the biosynthesis of aromatic polyketides, stereoselective arene-forming aldol condensation reactions were investigated to form configurationally stable binaphthalenes, axially chiral amides and oligo-1,2-naphthylenes. As this versatile strategy provides various rotationally restricted compounds with high enantioselectivity, it is expected to be of great use in many areas of application.
R. M. Witzig, D. Lotter, V. C. Fäseke, C. Sparr*

Page No. - Page No.

Stereoselective Arene-Forming Aldol Condensation: Atroposelective Synthesis of Axially Chiral Compounds 